\title{
Ardis, engenhos, maquinações: astúcias do padre Vieira
}

Marcos Antônio Lopes

Universidade Estadual de Londrina

$66 】$

mperador da Língua Portuguesa”, talvez seja a distinção mais justa e a que melhor caracteriza a grandeza literária do padre Vieira. Ao que tudo indica, essa figura polêmica passou a vida com a pena entre os dedos. Não se pode perder de vista que foram perto de setenta anos de atividade intelectual quase ininterrupta. De sua lavra contam-se, em diversos gêneros, perto de mil escritos. Os seus mais de duzentos sermões são a parte que melhor resistiu ao tempo, em termos de uma avaliação qualitativa da posteridade, pelo apuro da composição dos textos e pela riqueza da prosa. A densidade barroca de seus sermões está sobrecarregada de idéias bastante complexas, de raciocínios sinuosos, mas são bem fracos os traços da técnica ornamental que caracteriza a maior parte da literatura de época. O seu "discurso engenhoso" é um artefato criado para veicular idéias, e convencer pelo argumento, antes que deslumbrar ou atarantar pelo aparato de palavras bem arranjadas. "Se gostas da afectação e pompa de palavras e do estilo que chamam culto, não leias" escreveu Vieira no prefácio de seus Sermões. Nada de arte pela arte, nada de conceber a escrita para meramente agitar marés literárias.

Para expressar - em linguagem figurada -, uma teoria da ação nos Sermões, é possível afirmar que Vieira ajustava seu discurso como se estivesse comprimindo a carga de um arcabuz. A boca e a pena do autor expelem ferro e fogo; as suas palavras são "pistolas carregadas", ${ }^{1}$ metáfora que define a palavra como uma força que movimenta idéias e deflagra atitudes. Em

${ }^{1}$ A expressão é de Sartre. Citada por WINOCK, 2000, p. 518. 
um plano teórico, as ditas "pistolas carregadas", ou "sabres afiados", que caracterizam uma clara consciência na força criadora e transformadora das palavras, não são uma invenção sartriana; remontam, pelo menos, ao Iluminismo. Com efeito, lemos em um texto dos meados do século XVIII, que as palavras "Geralmente nada significam em si mesmas, mas pela maneira como são pronunciadas. Freqüentemente, repetindo-se as mesmas palavras, atribuímos a elas um sentido diferente, dependendo esse sentido de sua relação com outras coisas. (...) porque as palavras são ligadas à ação e dela participam". ${ }^{2}$ Fiel praticante de uma teoria do engajamento - a de sua própria Ordem -, a consciência da responsabilidade cristã, com Vieira, chegou a tal grau de definição, a ponto de se poder dizer dele, que não admitia alhear-se de nenhum problema de seu tempo, sempre enlaçado por muitos compromissos, voluntariamente assumidos em prol do reino de Portugal.

Mas foi o próprio Vieira quem declarou que a obra profética era a sua única contribuição relevante. Sua produção epistolar - composta por cerca de setecentas cartas - não possui o viço dos sermóes, mas trata-se de documentos reveladores, tanto da personalidade solar de seu autor, quanto de uma série de circunstâncias históricas vividas pela monarquia lusitana, nos meados do século XVII. Seus demais textos, qualificados por seus editores sob a rubrica de "obras várias", "papéis diversos" ou rótulos equivalentes, compõem-se dos já referidos textos proféticos, das peças de defesa do processo inquisitorial que enfrentou em Coimbra, além de alguns "artigos de intervenção", que versam sobre questões econômicas, estratégias políticas e conselhos ao rei de Portugal. É interessante notar que as duas "Propostas" dirigidas a D. João IV - a favor da admissão dos judeus mercadores, no comércio do reino (1643) e a favor da gente de nação

2 MONTESQUIEU, 1978, p. 175s. Se ainda não é a teoria dos "atos do discurso", tais idéias de Montesquieu talvez possam ser tomadas como um de seus prenúncios criadores, na forma como a utiliza o historiador inglês Quentin Skinner. Cf. os artigos "Motives, Intentions and the Explanation of Social Action" e "Some Problems in the Analysis of Political Thougth and Action”. In: TULLY, 1988. 
(1646) - alçam Vieira à honrosa categoria de um dos inventores da tolerância religiosa, nos Tempos Modernos. E isso muitas décadas antes de autores como Pierre Bayle, Leibniz e Locke terem começado a refletir sobre o assunto.

Vieira nasceu em Lisboa, nos inícios de 1608. Faleceu na Bahia, em meados de 1697. Numa existência quase centenária, essa figura ativa teve tempo de sobra para inquietar os poderosos, dos dois lados do Atlântico. Aliás, a sua vida adulta inicia-se por uma manobra radical: a saída de casa, para ingressar na Companhia de Jesus, sem o consentimento prévio dos pais. Com efeito, Vieira tornar-se-ia uma fonte incômoda de ruído, tanto na corte de D. João IV, quanto entre os colonos do Norte do Brasil. Expondo e defendendo resolutamente as suas idéias e projetos, arranjou inimigos às pencas. Em sua história de vida é possível encontrar instrutivas liçóes de como fazer adversários e fomentar a ira dos desafetos. Esgrimiu corajosamente, durante quatro longos anos, com a Inquisição, de 1663 a 1667, metade dos quais na condição de prisioneiro. A sua defesa desassombrada dos índios brasileiros, por exemplo, não deixa dúvidas quanto a seu destemor. Diante da resistência de Vieira à exploração dos indígenas, os colonos do Maranhão o embarcaram à força para a metrópole, bem como a todos os frades de sua Ordem, sob a iracunda gritaria de "abaixo os urubus!".

Mas, durante um bom tempo, Vieira foi amigo do rei, período em que esteve sob o escudo protetor representado pelo púlpito, por sua condição de Pregador Régio - cargo para o qual fora nomeado em 1644 - e, portanto, gozou de uma confortável liberdade de expressão. Como escreve um historiador português,

O púlpito, no seu tempo, era mais de uma vez a válvula de escape do comentário político, sendo com freqüência o sermão o equivalente aos editorais da imprensa do nosso tempo, de defesa ou ataque em face da situação, do fato, da providência governativa. Mas ninguém tanto como Vieira o converteu em posto de timoneiro ou cadeira de conselheiro de Estado, a cada passo mais debruçado sobre a terra do que olhando para o céu, e às Escrituras 
pedindo apenas as analogias, os exemplos, as imagens com que melhor pudesse autorizar os conselhos e sugestōes sobre matéria profana. ${ }^{3}$

Por sua coragem excessiva ou, quem sabe, por escassez de prudênciao que é quase a mesma coisa, e com certeza produz resultados semelhantes - embrenhou-se nos cipoais mais intrincados da política. Quando em movimento em torno de alguma causa, nada o detinha. Provocando corporaçóes inteiras, colidiu frontalmente com os Dominicanos no "Sermão da Sexagésima”. E teve audácia suficiente para tentar promover a sublevação dos súditos napolitanos contra o rei da Espanha, ao mesmo tempo em que tentava arranjar o casamento do príncipe português com a herdeira do rei espanhol. Sua intrepidez fica ainda mais realçada ao encarar de peito aberto a truculência dos potentados seculares nas províncias ultramarinas do Maranhão e do Pará. Minando a paciência e acicatando a intolerância do Santo Ofício, Vieira seguiu o seu arriscado caminho.

E não parece que lhe faltasse uma compreensão mais clara dos vários gumes da política. Algumas passagens de seus sermões e de seus textos de estratego político - pelos conselhos ardilosos que oferece ao príncipe revelam os caracteres da figura matreira que fazia quando em trânsito pelas altas esferas do mando. Mas, contra as evidências do real alcance de Vieira das dimensões menos nobres da política e de sua verdadeira percepção das instabilidades do poder, estão a íntegra de seus próprios textos, e os exemplos de sua vida. Como o cortesão de Dionísio, ${ }^{4}$ Vieira se aproximou do trono para louvar a felicidade de um rei para o qual Deus havia reservado nada menos que as glórias de imperador da Cristandade Universal. Mas

${ }^{3}$ CIDADE, 1973, p. 172.

${ }^{4}$ Refiro-me a Dâmocles, "favorite of Dionysius of Syracuse, who caused a sword to be suspended over his head by a single horse-hair". Vários Autores. Verbete "Damocles". In: The New Concise Encyclopedia, p. 304. Ao elogiar a felicidade de Dionísio (século IV a.C.), este o fez sentar-se no trono. O sentido alegórico da espada suspensa por um fio de cabelo está na instabilidade e nas preocupaçóes sempre movediças do poder. 
longe dele certas inocências úteis dos intelectuais seduzidos pelo poder: ele sabia dos riscos e perigos de um trono, que cobra tributos muito elevados aos príncipes, notadamente naquela última prestação de contas, diante da qual não há apelação. Essa sua crença numa justiça divina implacável pode ser identificada, dentre vários textos de sua lavra, na "Carta a D. Afonso VI", de 20 de abril de 1657: "Senhor, os reis são vassalos de Deus, e, se os reis não castigam os seus vassalos, castiga Deus os seus". 5

O término do reinado de D. João IV, em 1656, deu ampla liberdade de movimentos àqueles que, durante quinze anos, mantiveram a espada suspensa sobre a cabeça do até então homem dos sete instrumentos da monarquia lusitana. Sob a mira do Santo Ofício desde 1649, quando ocorreram as primeiras denúncias contra si, as suas desventuras mais sérias tiveram início em 1661, ano da expulsão dos jesuítas do Maranhão. Dois anos depois, já no turbulento reinado de D. Afonso VI - contra o qual se manifestara, em favor do irmão mais moço - foi desterrado para Coimbra, a pedido da Inquisição. Após a sua reclusão ao cárcere, em 1665, outras agruras sobrevieram. O Breve Pontifício de 1675 absolveu-o das penas impostas pelo Santo Ofício em 1667, além de anular, em Portugal, a jurisdição inquisitorial sobre a sua pessoa. Foi no ano de 1675 que Vieira decidiu partir de Roma para Lisboa, movido pela esperança de recuperar a antiga influência sobre o trono. No entanto, as suas expectativas foram frustradas por D. Pedro, então príncipe regente desde o golpe de Estado de 1667. Na cena política portuguesa, após seu regresso da Itália, a máxima projeção que alcançou foi uma participação na Junta de Conselheiros de Estado, em 1680.

Pouca coisa havia restado de seu antigo prestígio. Foi quando sentiu que era chegada a hora de bater em retirada. Após o seu retorno ao Brasil - ocorrido em 1681 -, estudantes fanáticos de Coimbra queimaram-no em efígie. Pouco tempo depois, foi acusado de participar das maquinaçóes, que culminaram em um atentado contra um membro da elite política baiana. Décadas depois de sua morte, já nos meados do século XVIII, houve quem

${ }^{5}$ VIEIRA. Carta a D. Afonso VI. In: TEIXEIRA (Org.), 1949, p. 195. 
lhe atribuísse a autoria de um escrito polêmico: $A$ arte de furtar. ${ }^{6}$ Dos meados do século XVIII data também a sua primeira biografia, de autoria de seu confrade e grande admirador, André de Barros. De lá para cá vem se acentuando o interesse por Vieira, haja vista a profusão das edições de sua obra. Na seqüência destes apontamentos biográficos, gostaria de desenvolver brevemente, a título de notas prévias, de uma pesquisa em estágio ainda inicial, algumas observaçôes sobre os ideais utópicos do padre Vieira.

As utopias modernas foram várias, a começar pelo clássico de Thomas Morus que, no gênero, ocupa um lugar tão destacado, que pouco se ouve falar de outras concepções utópicas Quinhentistas. Mas, acerca de concepções dos lugares imaginários, o século XVII também foi exuberante. Os ideais utópicos apareceram de forma vigorosa em diferentes linhagens literárias, das quais dão mostras Francis Bacon, Tomaso Campanella, James Harrigton. O próprio Bacon, um dos artífices da cultura científica moderna, fez a sua incursão no gênero, ao propor uma espécie de reforma da natureza das sociedades humanas com a sua Nova Atlântida. ${ }^{7}$

O gênero utópico que persistiu na cultura intelectual européia, ao longo do século XVI, e que persistirá também no XVII, não apresenta nenhum traço de anacronismo. Isso significa que, no tempo de Vieira, a utopia era uma idéia em seu lugar natural, como havia sido antes e como seria inclusive depois, já no século XIX, haja vista que as promessas do mundo moderno que foi se constituindo aos poucos, não resolveram alguns problemas cruciais das comunidades políticas; significa também que a utopia é um gênero de vários matizes, e que se desenvolve em descompasso com as circunstâncias do mundo real. Se é assim, pode-se dizer que a voga das utopias no século XVII tem a ver com as muitas e rápidas transformaçôes, que tornaram o mundo estranho e hostil, para os homens daquele tempo. Daí o desejo ou a necessidade de se escapar de uma vida violenta e absurda, segundo a percepção de alguns escritores, entre os quais o padre Antônio Vieira.

\footnotetext{
${ }^{6}$ Cf. ANÔNIMO DO SÉCULO XVIII, 2005.

7 Todas essas obras possuem edições pela Abril Cultural na Coleção Os Pensadores.
} 
Com os seus engenhos de inteligência, o ilustre jesuíta deu mostras de que era possível superar o sofrimento provocado por um mundo desordenado pelas guerras. O livro História do Futuro narra a história de um grande projeto: o da constituição de uma nova ordem mundial. ${ }^{8}$ A História Sagrada do padre Vieira mistura a realidade das coisas humanas com um projeto divino, esboçado para se realizar em futuro, não muito distante de seu próprio tempo. Para Vieira, esse projeto foi traçado por Deus, nas Escrituras, mas dependia de açóes humanas para que pudesse se concretizar inteiramente. É assim que a história do reino de Portugal vai sendo posta em movimento, pela imaginação criadora do autor. Ações humanas e assistência divina são os agentes desencadeadores de um grande futuro para o povo lusitano, futuro que se revela pela interpretação das "astúcias celestes", que Vieira vai desvendando, em sua condição de intérprete autorizado das Sagradas Escrituras. O livro inacabado do padre Vieira foi concebido como expediente de esclarecimento dos príncipes e dos interessados em conhecer os mais escuros mistérios da história.

Mas qual seria o sentido atribuído pelo próprio autor à idéia do Quinto Império? É certo que a sua imaginação ultra-fértil fundamentouse numa já consolidada interpretação das profecias bíblicas de Daniel, acerca dos quatro impérios sucessivos, que se alternavam do Oriente sempre em direção ao Ocidente. Vieira enxergou nas alternâncias geográficas dos impérios assírio, persa, grego e romano uma realização secreta e antecipada das culminâncias da história humana sobre a terra, que teria como resultado final o império lusitano. Segundo ele, uma razão superior orientava o sentido do mundo para o Quinto Império. Antes mesmo, da elaboração das concepções vieirianas, os textos lusitanos de História apelavam para um destino glorioso de Portugal como se isso fosse uma exigência do plano de Deus para o mundo. A celebração da façanha de Ourique era um desses grandes exemplos das coisas passadas, a reafirmar um futuro de glórias para a nação. Sob esse aspecto, Vieira estava perfeitamente integrado ao sistema de crenças populares de seu tempo, pois, também imaginava que Deus

${ }^{8}$ Atualmente, utilizo a seguinte edição: VIEIRA, 2005. 
descera à terra para fundar um novo reino e que, na ocasião, palestrara com o rei D. Afonso Henriques, acerca de tema de tão alto relevo. Contudo, Vieira ponderou que havia sutilezas que precisavam ser observadas para o pleno êxito de tal projeto: se, por um lado, a existência terrena é um drama teleológico, cujo sentido já está definido antes de se completar, a história não deixa de requerer ações humanas bem dirigidas. É que a Providência cobra dos homens a sua parte, na realização dos sucessos mais grandiosos. Assim, fazer o que compete a cada um, em sua própria esfera de obrigaçôes, era um dever incontornável.

Uma guinada teórica da qual Vieira parece ter clara consciência de ser o promotor refere-se à dimensão temporal de sua História. Os exemplos das coisas passadas possuem uma utilidade programática, que ele utilizou para os seus propósitos de convencimento. Ao ler as profecias de grandes visionários como Isaías e Daniel, o jesuíta procurou manejá-las de maneira que pudessem ser apontadas como os juízos de realização, das suas próprias expectativas. Seria assim, que Portugal tornar-se-ia a ponta de lança da Cristandade, naquela fase da história, que ele denominou o Quinto Império, em que a roda da Providência faria correr, em definitivo, do Oriente ao Ocidente, todos os movimentos políticos decisivos para o advento de uma nova era. Conforme ele assegura no "Sermão de ação de graças pelo nascimento do príncipe D. João", a sucessão cronológica e geográfica das monarquias universais "... vai levando seu curso para o Ocidente, havendo de ser, como é de fé, o último império, aonde pode ir parar, senão na gente mais ocidental de todas?". ${ }^{9}$

Manejando as Sagradas Escrituras como instrumento de persuasão, que concentra o juízo de autoridades incontestáveis da melhor tradição teológico-religiosa, Vieira manipulou os acontecimentos do passado, apontando-os como a garantia infalível do que estava por vir. As profecias são escudos defensivos, afirma ele na História do Futuro, pois o que está escrito nos Testamentos é a própria garantia infalível do sucesso. Assim, conhecer o futuro é como tentar enxergar nas trevas mais espessas. O futuro

${ }^{9}$ VIEIRA, 1951, p. 84, Volume XV. 
é matéria obscura, e requer a sensibilidade do profeta. Andar nas trevas e desembaraçar-se dos perigos da escuridão, só se for impelido pelo Espírito Santo. A candeia da profecia é o instrumento de iluminação dessas trevas espessas, o futuro. Para Vieira, os exemplos da História Sagrada narrados nas Escrituras eram suficientes para demonstrar ser Portugal a terra da promissão. De fato, ele via Portugal como o país do futuro, o novo centro civilizador de uma Cristandade, até então, necessitada de bons corretivos.

Ele, Vieira, percebia-se então como o cronista credenciado para narrar as venturas que estavam por vir. Ademais, pretendia revelar tantas glórias reservadas por Deus à sua pátria a ponto de silenciar todas as Histórias que abordaram as passadas conquistas portuguesas. O novo reino, do qual já se enxergavam os prenúncios, não seria formado por "retalhos de terra". Os seus limites geográficos, considerou Vieira, teriam por "margens os horizontes". O Quinto Império não seria apenas um título vago ou meramente teórico, como o Sacro Império Romano Germânico de seu tempo; seria não menos que a união de todos os cetros cristãos. Haveria uma única coroa secular e a Providência se encarregaria de manter o equilíbrio permanente desse colosso territorial.

Por suas intervenções muitas vezes consideradas impertinentes por seus adversários, Vieira foi denunciado à Inquisição portuguesa, a propósito de judaísmo e também pelas idéias proféticas de seu imaginativo Quinto Império. De fato, trata-se de leituras bem visionárias das Sagradas Escrituras. O clérigo torce e retorce textos, usa e abusa dos direitos de sua "fornalha da imaginação" (António Sérgio), em tempos não mais seguros para intérpretes de mistérios. ${ }^{10}$ Ora, de fato é possível pensar no padre Vieira como um imaginativo decifrador de mistérios, para servir à construção de um projeto político. Por seu destemor diante de tantas circunstâncias que lhe cobraram ações corajosas, em prol da monarquia lusitana, talvez seja mesmo pertinente pensar em Vieira como um líder de infantaria, o homem que marcha à frente das tropas, transmitindo a mensagem de ânimo, ao mesmo tempo em que vai anunciando os prenúncios do êxito.

${ }^{10}$ SÉRGIO. Prefácio. In: VIEIRA, 1951. Carta I, Volume I. 
Mas, como a realidade deste mundo é inconstante, de uma hora para outra, o arauto das excelências da monarquia lusitana tornou-se um desvalido. A morte do rei, decorridos cerca de quinze anos de sua presença como um dos mais prestigiados membros da corte lusitana (Vieira chegara em Lisboa nos inícios de 1641 para manifestar apoio pela restauração da monarquia), foi como se lhe tivessem retirado o chão. Faltava assim ao criativo encenador o protagonista de sua grande peça. $\mathrm{Na}$ ausência do príncipe perfeito entre os vivos, para a consumação de seu Quinto Império, Vieira chegou à solução fantástica da ressurreição de D. João IV. Para ele, as ressurreições, na história, não eram apenas possíveis, mas até muito freqüentes. Elas ocorreriam para consumar desígnios da Providência. Por isso, Vieira apoiou-se na certeza de que Deus pode derrogar a lei da morte, como fez com Lázaro. E o ator, que transformaria a difícil realidade da monarquia lusitana, a caminho do Quinto Império, não seria, necessariamente, um personagem fixo. Vieira vai alternando as figuras - por ressurreição ou simples transferência -, à medida que a realidade contrariava os seus prognósticos. Aliás, a realidade foi particularmente persistente em desconfirmar as previsões do escritor, mormente quanto a tudo aquilo que dissesse respeito ao Quinto Império. Mas, a esses desmentidos, Vieira sempre contrapunha golpes de imaginação, inspirados nas Escrituras. Nos textos bíblicos ele encontrava algumas saídas criativas para explicar todas as profecias não confirmadas, e assim foi adiando a realização das promessas pelo argumento que, na história dos homens, é muito difícil perceber uma conclusão, um arremate mais definitivo nos eventos.

Essas agudezas, esses ardis, esses golpes de espírito, esse "discurso engenhoso" confirmam a sua fé no grande futuro da monarquia. A sua capacidade de imaginação permitiu-lhe explicar a orgulhosos leitores de outras terras - mormente os de reinos maiores e mais poderosos como Espanha, França, Inglaterra - a pertinência de uma, por assim dizer, Cristandade Universal, liderada por um reino tão pequeno como Portugal. A resposta estava na própria história deste reino: nasceu de uma aliança com Cristo, e desvendou todos os mundos até então desconhecidos. Portanto, Portugal estava justificado como a cabeça da Cristandade, por ser o reino 
eleito, encarregado da maior missão histórica de um povo sobre a terra: a realização de uma unidade política e religiosa universal. Como escreveu o historiador Hernani Cidade, acerca dos anseios populares seiscentistas, em torno de monarquia universal, análise que demonstra o enraizamento cultural das eruditas idéias de Vieira

A radiosa esperança pregava-se nos púlpitos, era tema de sabatinas escolares, propagava-se entre nobres e plebeus, entre cultos e ignorantes; aceitavam-na lentes das Universidades, mas sobretudo a prestigiavam e defendiam os professores jesuítas da Universidade de Évora ...11

Após a morte de D. João IV e, alguns anos mais tarde, com o término da regência de Dona Luísa de Gusmão, iniciaram-se as desventuras de Vieira. Até então, ele era um dos mais prestigiados cortesãos. Alcançado, finalmente, por seus adversários, mutatis mutandis, ele logo se viu tão desarmado como o Savonarola descrito por Maquiavel. $\mathrm{O}$ amigo do rei não contava mais com os seus patronos. $\mathrm{O}$ antigo valido encontrava-se numa situação de isolamento, figura, agora frágil, diante dos numerosos inimigos que fora empilhando em sua passagem. No ano de 1663, estava em curso o instável reinado de D. Afonso VI. Seguindo a orientação de sua Ordem religiosa, Vieira apoiara, poucos anos antes, a ascensão de D. Pedro, o irmão caçula do herdeiro, então julgado por uma cúpula de figuras de prol, como a presença mais adequada, para as complexas lides de um governo, ainda, na corda bamba, insegurança sentida, principalmente, pela presença da sempre inconformada e aguerrida Espanha.

Enquanto os ventos estiveram a seu favor, foi fácil para Vieira polemizar, sem o temor de afrontar os interesses de inquisidores fanáticos, a equívoca e incerta opinião popular, e a conservadora vontade dos cortesãos. O tribunal da Inquisição de Coimbra requisitou-o, nos inícios da década de 1660. Habilidade e eloqüência não bastavam mais, para manter essa usina de idéias, longe da ira de seus antagonistas, na "Ilha da Purificação",

${ }^{11}$ CIDADE, 1973, p. 178. 
conforme as alusões de alguns autores à Península Ibérica, nos tempos da Contra-Reforma, quando Portugal e Espanha se fecharam a todo movimento de idéias novas, que estavam surgindo na Europa. A expressão pode ser utilizada no sentido de zelo da ortodoxia, zelo que formou barreiras ao trânsito das novas concepções, mormente no campo das ciências.

Não há dúvida de que a História do Futuro foi um investimento profético, no qual Vieira traçou o projeto de uma nova era, os mil anos gloriosos dos eleitos sobre a terra. Nessa Cristandade regenerada, o novo monarca universal não dividiria o seu poder com nenhum outro ator político secular; mas ele o compartilharia com o imperador espiritual da Cristandade. O Quinto Império representaria o alinhamento do cetro secular do imperador, com o báculo espiritual do papa, com vistas à consumação do reinado de Cristo na terra. Nesse novo mundo, judeus, maometanos e gentios seriam convertidos à verdadeira fé. Ao que parece, um esforço intelectual da magnitude da História do Futuro não era tarefa para, simplesmente, cair no espaço ocupado por pessoas intelectualmente ociosas e politicamente desatentas. Em se tratando, inegavelmente, de uma obra tão relevante, nada haveria de negativo, em alardear este imenso bem realizado, em nome do gênero humano. $\mathrm{O}$ autor visava, com o seu texto, atingir um conjunto de leitores importantes que lhe aprovassem o esforço.

Se havia um diferencial em sua projetada História do Futuro, que de fato pudesse impressionar as mentes mais conservadoras, ainda indiferentes ao plano divino por ele narrado, Vieira acreditava que o tempo se encarregaria de lhe dar razão, demovendo assim os descrentes. De suas próprias circunstâncias - haja vista que os seus textos proféticos foram requisitados pela Inquisição, nos inícios do reinado de D. Afonso VI -, Vieira sacou o exemplo de São Jerônimo. A sua Vulgata não fora perseguida e condenada em seu tempo? E que brilhante futuro se descortinou para a sua tradução! O triunfo de suas próprias verdades, logo deveria mostrar os seus vigorosos efeitos. Questão de tempo, iludia-se Vieira. Na verdade, o projeto político, no qual ele investiu uma parte considerável de seus talentos, era uma realidade já superada, pelos Tempos 
Modernos. De fato, quimérica foi a visão de Vieira, que apostou na idéia de império universal, em plena época de ascensão das monarquias nacionais.

Para a História das Idéias, os numerosos desacertos do intuitivo jesuíta são temas relevantes para a reflexão. De fato, a simples existência de um texto tão fantástico - em variadas acepções do termo -, enriquece a nossa tradição literária. Mesmo considerando que a História do Futuro foi um projeto que ficou em germe, haja vista que Vieira escreveu apenas uma espécie de amplo preâmbulo ao texto que seria, segundo ele mesmo, sua obra magna, ainda assim seu livro inacabado é grandioso e, com certeza, a maior e a melhor de nossas utopias.

Há quem afirme - como o brasilianista Stuart Schwartz - que o século XVII europeu produziu grandes figuras literárias, mas que, nenhuma pode ser situada acima de Vieira. "Hércules do verbo", "Imperador da língua portuguesa”, "Cícero Lusitano", "prestidigitador" e "pirotécnico”, Vieira suscitou o espanto, provocou a estranheza, deslumbrou as mentes, estarreceu o público. Sem dúvida, ele foi realmente o mais imaginativo moralista do Barroco português. Aliás, foi bem mais do que um autor imaginativo. Ele fez das "imagens sonoras", de sua literatura, uma máquina de guerra, contra os males de seu tempo. Numa certa altura de sua existência, pelos desgastes naturais da vida política, alcançou a proeza de unir a todos contra os seus ideais. Fato curioso, as suas glórias pessoais, ele as havia alcançado abrindo caminho com a política. Mas foi a política que o transformou naquele conhecido e visado escavador de precipícios. A política o guindou ao poder, a política o separou dele. Para lembrar uma passagem literária de A Ilustre Casa de Ramirez, de Eça de Queirós, que ilustra à perfeição as glórias e infortúnios de Vieira, isso "é o que se chama a inconstância dos tempos e do impérios". 


\section{Referências bibliográficas}

ANÔNIMO DO SÉCULO XVIII. Arte de furtar. Porto Alegre: L\&PM, 2005

CIDADE, Hernani. Portugal histórico e cultural. Lisboa: Círculo de Leitores, 1973.

MONTESQUIEU. Do Espírito das Leis. São Paulo: Abril Cultural, 1978.

SÉRGIO, Antônio. Prefácio. In: VIEIRA, Antônio. Obras escolbidas do padre Antonio Vieira. Porto: Lello \& Irmão, 1951. Carta I, v. I.

SKINNER, Quentin. Motives, Intentions and the Explanation of Social Action. In: TULLY, James (Ed.). Meaning and Context. Quentin Skinner and his Critics. Cambridge: Polity Press/Basil Blackwell, 1988.

SKINNER, Quentin. Some Problems in the Analysis of Political Thougth and Action. In: TULLY, James (Ed.). Meaning and Context. Quentin Skinner and his Critics. Cambridge: Polity Press/Basil Blackwell, 1988.

THE NEW CONCISE ENCYCLOPEDIA. New York: Doubleday, Doran and Company, 1949.

VIEIRA, António. Carta a D. Afonso VI. In: TEIXEIRA, Novais (Org.). Cartas. Rio de Janeiro: W. M. Jackson Editores Inc., 1949.

VIEIRA, Antônio. História do Futuro. Brasília: Editora da UnB, 2005. (Organização: José Carlos Brandi Aleixo)

VIEIRA, Antônio. Sermão de ação de graças pelo nascimento do príncipe D. João, primogênito de SS. Magestades, que Deus guarde (1688). In:

Obras completas do padre Antonio Vieira. Porto: Lello \& Irmão, 1951. v. XV. WINOCK, Michel. O século dos intelectuais. Rio de Janeiro: Bertrand Brasil, 2000 . 


\section{Resumo}

A História Sagrada do padre Vieira mistura a realidade das coisas humanas com um projeto divino, esboçado para se realizar, em futuro não muito distante do tempo vivido pelo autor. Este projeto foi traçado por Deus, nas Escrituras, mas depende de ações humanas, para que possa se realizar inteiramente. É assim que a história do reino vai sendo encadeada. Ações humanas e assistência divina são os agentes desencadeadores de um grande futuro, que vai sendo revelado aos portugueses, pelo intérprete autorizado. Este artigo aborda alguns aspectos das "astúcias celestes", das quais Vieira foi um atento e inspirado leitor.

\section{Abstract}

Father Vieira's Holy History mixes the reality of human things with a divine project outlined to be carried out in a future not so distant from the time lived by the author. This project was drawn up by God in the Holy Scriptures, but it depends on human action in order to be carried out completely. That is the way the Kingdom history is being linked. Human actions and divine assistance are the triggering agents of a great future that is being revealed to the Portuguese people by the authorized interpreter. This article deals with some aspects of the "heavenly subtleties" of which Vieira was an attentive and inspired reader. 